\title{
Oesophageal motility and gastro-oesophageal reflux before and after healing of reflux oesophagitis. A study using 24 hour ambulatory $\mathrm{pH}$ and pressure monitoring
}

\author{
R Timmer, R Breumelhof, J H S M Nadorp, A J P M Smout
}

\begin{abstract}
In this study 24 hour oesophageal pH and pressure monitoring was used to assess oesophageal motility and acid clearance in 27 patients with reflux oesophagitis (Savary-Miller grades I-IV), before and after healing of oesophagitis. After the first 24 hour study patients were treated with omeprazole $40 \mathrm{mg}$ for 8-24 weeks. After endoscopically verified healing and withdrawing omeprazole for four days 24 hour monitoring was repeated. A total of 106630 pressure events was analysed. No significant differences were found for any of the motility variables, especially the number and the type of contractions, the peristaltic amplitude, duration, and propagation velocity did not show any changes. Separate analysis of motility variables before and after healing in the low and high grade oesophagitis groups yielded similar results. Oesophageal motor response to reflux was investigated by analysis of all contractions occurring in the two minute period after the onset of each reflux episode. Both motor response and oesophageal acid exposure (\% time pH $<4$, number of reflux episodes) did not change after healing of oesophagitis, thus implying that acid clearance remained unchanged. These results indicate that impaired motility in reflux oesophagitis is either an irreversible consequence of oesophageal inflammation, or a (preexistent) factor in its pathogenesis.

(Gut 1994; 35: 1519-1522)
\end{abstract}

The key part in preventing gastro-oesophageal reflux is played by the lower oesophageal sphincter (LOS). In gastro-oesophageal reflux disease the basal LOS pressure may be decreased, or may show an increased frequency of spontaneous transient relaxations, the most prevalent mechanism in low grade

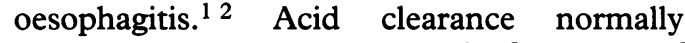
occurs as a two step process. At first most of the refluxed volume is cleared quickly by one or two peristaltic contractions, thereafter the remaining acid is neutralised by swallowed saliva. $^{3}$

Oesophageal motility has been shown to be impaired in a subset of patients with reflux oesophagitis, especially in patients with high grade reflux oesophagitis. A few studies have now been published that found no improvement in oesophageal motility after healing of oesophagitis. ${ }^{45}$ In these studies the method used to assess oesophageal motility was conventional manometry. It is now possible to study motility under more physiological circumstances and for longer time periods, using 24 hour ambulatory recording devices with computerised analysis of data. This makes it possible to study different time periods separately, such as between and during meals, upright and supine periods, and the periods immediately after each $\mathrm{pH}$ decrease. ${ }^{6}$

We used 24 hour ambulatory monitoring to assess oesophageal motility in patients with reflux oesophagitis before and after healing of oesophagitis.

\section{Methods}

Twenty seven patients ( 6 women and 21 men), mean age 56 years (range 25-83), with endoscopically confirmed reflux oesophagitis, were studied twice, once before and once after healing of their oesophagitis. The reflux oesophagitis was graded according to the Savary-Miller classification.

Thirteen patients had grade I oesophagitis (superficial linear erosions), five grade II (confluent non-circumferential erosions), five grade III (circumferential erosions), and four grade IV (ulceration or stenosis). Thirteen patients had a sliding hiatal hernia of more

\begin{tabular}{|c|c|c|c|}
\hline $\begin{array}{l}\text { Lower oesophageal sphincter pressure }(\mathrm{kP} \\
\text { Proximal peristaltic amplitude }(\mathrm{kPa}) \\
\text { Proximal peristaltic duration }(\mathrm{s}) \\
\text { Distal peristaltic amplitude }(\mathrm{kPa}) \\
\text { Distal peristaltic duration }(\mathrm{s})\end{array}$ & $\begin{array}{l}1.27(0 \cdot 10) \\
5.86(0.68) \\
1.89(0.15) \\
6.97(0.78) \\
1.99(0.12)\end{array}$ & $\begin{array}{l}1.38(0 \cdot 13) \\
6 \cdot 37(0 \cdot 93) \\
1.99(0 \cdot 19) \\
8 \cdot 29(1 \cdot 00) \\
2 \cdot 17(0 \cdot 13)\end{array}$ & $\begin{array}{l}1.06(0 \cdot 14) \\
4.91(0 \cdot 76) \\
1 \cdot 69(0 \cdot 22) \\
4.49(0 \cdot 67) \\
1.63(0 \cdot 19)\end{array}$ \\
\hline
\end{tabular}

*Significance of difference between low and high grade oesophagitis subgroups. NS $=$ not significant. The data from one patient were discarded because of technical problems. 
TABLE II Gastro-oesophageal reflux variables in patients with reflux oesophagitis grade $I \wedge I V$ before and after healing of reflux oesophagitis (median and range)

\begin{tabular}{|c|c|c|c|}
\hline \multirow[b]{2}{*}{ Grades I-IV } & \multicolumn{2}{|l|}{ Healing } & \multirow{2}{*}{$\stackrel{p}{\text { Value }}$} \\
\hline & Before & After & \\
\hline \multicolumn{4}{|l|}{ Percentage recording time $\mathrm{pH}<4$} \\
\hline Total & $13 \cdot 0(2 \cdot 6-38 \cdot 2)$ & $12 \cdot 0(2 \cdot 2-36 \cdot 0)$ & NS \\
\hline Upright & $13 \cdot 6(1 \cdot 3-39 \cdot 7)$ & $14 \cdot 4(3 \cdot 3-36 \cdot 7)$ & NS \\
\hline Supine & $5 \cdot 3(0 \cdot 0-51 \cdot 0)$ & $5.9(0.0-66.5)$ & NS \\
\hline Total no of reflux episodes $(\mathrm{pH}<4)^{\star}$ & $66 \cdot 0(23-167)$ & $67 \cdot 2(28-171)$ & NS \\
\hline Total no of reflux episodes $>5 \mathrm{~min}^{\star}$ & $7 \cdot 3(0 \cdot 0-25 \cdot 9)$ & $7 \cdot 0(0 \cdot 0-22 \cdot 3)$ & NS \\
\hline \multirow{2}{*}{\multicolumn{3}{|c|}{ Percentage recording time $\mathrm{pH}<4$}} & \\
\hline & & & NS \\
\hline Upright & $14 \cdot 6(4 \cdot 1-30 \cdot 2)$ & $14 \cdot 4(3 \cdot 3-26 \cdot 8)$ & NS \\
\hline Supine & $4.8(0.0-40 \cdot 0)$ & $5.9(0.0-56 \cdot 6)$ & NS \\
\hline Total no of reflux episodes $(\mathrm{pH}<4)^{\star}$ & $65 \cdot 3(23-131)$ & $61 \cdot 4(28-116)$ & NS \\
\hline Total no of reflux episodes $>5 \mathrm{~min}^{\star}$ & $7 \cdot 3(0 \cdot 0-21 \cdot 6)$ & $6 \cdot 1(0 \cdot 0-22 \cdot 7)$ & NS \\
\hline $\begin{array}{l}\text { Grades III and } I V(\mathrm{n}=7) \\
\text { Percente } \mathrm{H}<4\end{array}$ & & & \\
\hline \multicolumn{4}{|l|}{ Percentage recording time $\mathrm{pH}<4$} \\
\hline Total & $14 \cdot 9(7 \cdot 6-38 \cdot 2)$ & $19 \cdot 2(11 \cdot 9-36)$ & NS \\
\hline Upright & $12.4(1.3-39 \cdot 7)$ & $15 \cdot 2(9 \cdot 2-32 \cdot 2)$ & NS \\
\hline Supine & $11 \cdot 1(2 \cdot 8-51 \cdot 0)$ & $16.9(1.5-66.5)$ & NS \\
\hline Total no of reflux episodes $(\mathrm{pH}<4)^{\star}$ & $109 \cdot 9(50-167)$ & $93 \cdot 0(56-171)$ & NS \\
\hline Total no of reflux episodes $>5 \mathrm{~min}^{\star}$ & $10.9(3.0-25 \cdot 9)$ & $11 \cdot 1(6 \cdot 4-22 \cdot 3)$ & NS \\
\hline
\end{tabular}

*Numbers normalised to 24 hours. In two patients with high grade oesophagitis one of the $\mathrm{pH}$ studies was discarded because of catheter failure.

than $2 \mathrm{~cm}$. Patients with strictures that could not be easily passed by the routinely used gastroscope (diameter $10 \mathrm{~mm}$ ) were excluded.

Patients who used acid inhibiting drugs at the time of endoscopy were excluded. Conventional manometry was carried out in the fasting state, using a water perfused system after all drugs that might affect oesophageal motility had been stopped for at least 48 hours. The LOS pressure and oesophageal peristaltic pressures 5 and $15 \mathrm{~cm}$ above the LOS were assessed. Thereafter, the solid state pressure catheter (containing two transducers $10 \mathrm{~cm}$ apart) and the $\mathrm{pH}$ catheter were positioned with the distal pressure sensor and the tip of the $\mathrm{pH}$ probe $5 \mathrm{~cm}$ above the upper border of the LOS. Detailed descriptions of the manometric methods used were published previously. ${ }^{6}$

The day after the 24 hour monitoring patients were given omeprazole $40 \mathrm{mg}$ once a day. Eight weeks later an upper endoscopy was done to check for healing of the oesophagitis. Omeprazole was continued for another eight weeks if the oesophagitis had not healed and endoscopy was then repeated. In four patients the oesophagitis took 24 weeks to heal. Within seven days after endoscopically confirmed healing of oesophagitis a second 24 hour ambulatory oesophageal monitoring

TABLE III 24 Hour ambulatory oesophageal peristaltic motility variables during upright interprandial, perprandial, and supine periods, before and after healing of oesophagitis, in patients with low and high grade oesophagitis (mean (SEM))

\begin{tabular}{|c|c|c|c|c|}
\hline & \multicolumn{2}{|l|}{ Low grade } & \multicolumn{2}{|l|}{ High grade } \\
\hline & Before & After & Before & After \\
\hline \multicolumn{5}{|c|}{ Amplitude ( $(\mathrm{PPa})$ (distal sensor) } \\
\hline $\begin{array}{l}\text { Interprandial } \\
\text { Perprandial } \\
\text { Supine }\end{array}$ & $\begin{array}{l}5.15(0.40) \\
6.43(0.61) \\
5.98(0.44)\end{array}$ & $\begin{array}{l}5.16(0.38) \\
6.41(0.58) \\
6.31(0.47)\end{array}$ & $\begin{array}{l}5.91(0.51) \\
6.81(0.82) \\
6.73(0.58)\end{array}$ & $\begin{array}{l}5.50(0.25) \\
6.58(0.48) \\
6.58(0.47)\end{array}$ \\
\hline \multicolumn{5}{|c|}{ Duration (s) (distal sensor) } \\
\hline Interprandial & $1.78(0.09)$ & $1.75(0.08)$ & $1 \cdot 77(0 \cdot 07)$ & $1.84(0.07)$ \\
\hline Perprandial & $1.92(0.12)$ & $1.82(0 \cdot 10)$ & $2.04(0 \cdot 10)$ & $2 \cdot 14(0 \cdot 16)$ \\
\hline Supine & $2 \cdot 76(0 \cdot 21)$ & $2.63(0.15)$ & $2.47(0.21)$ & $2.48(0.19)$ \\
\hline \multicolumn{5}{|l|}{ Velocity $(\mathrm{cm} / \mathrm{s})$} \\
\hline Interprandial & $3.43(0.12)$ & $3.45(0 \cdot 10)$ & $3.72(0 \cdot 16)$ & $3.86(0.17)$ \\
\hline Perprandial & $2.93(0.07)$ & $2 \cdot 90(0 \cdot 07)$ & $3 \cdot 15(0 \cdot 13)$ & $3 \cdot 29(0 \cdot 20)$ \\
\hline Supine & $4 \cdot 10(0 \cdot 23)$ & $4.03(0.13)$ & $3.81(0.22)$ & $4 \cdot 19(0 \cdot 36)$ \\
\hline
\end{tabular}

was performed, four days after stopping omeprazole.

On completion of the 24 hour monitoring, all recorded data were transferred to a computer, stored on a floppy disk, and analysed in a fully automated way, using previously validated and published algorithms. ${ }^{89}$

The $\mathrm{pH}$ data were analysed by calculating the percentage of time with $\mathrm{pH}<4$ for the upright, supine, and total 24 hour period, the total number of reflux episodes, and the number of reflux episodes lasting longer than five minutes.

Other previously described computer algorithms ${ }^{6}$ were used to study all contractions occurring in the two minute period after the onset of each reflux episode, a reflux episode being defined as a fall in $\mathrm{pH}$ to a value $<4$ that lasted longer than 24 seconds.

Motility before and after healing and $\mathrm{pH}$ values were compared using the Wilcoxon test for paired observations. $\mathrm{pH}$ Results are expressed as median with range and motility variables as mean (SEM), unless stated otherwise. A $p$ value $\leqslant 0.05$ is considered significant.

\section{Results}

As Table I shows, conventional manometry showed a significantly lower amplitude and duration of distal peristaltic waves in the high grade oesophagitis group. There was a trend towards a lower oesophageal sphincter pressure in high grade oesophagitis, but this was not statistically significant.

Table II shows the 24 hour $\mathrm{pH}$ characteristics of the patient group as a whole and for the low and high grade oesophagitis groups separately. Patients with high grade oesophagitis showed a trend towards a higher acid exposure, especially at night, but this failed to reach statistical significance.

Reflux variables before and after healing of reflux oesophagitis were not statistically different, both for the total group and for the low or high grade groups separately.

A total of 106630 pressure events was analysed. The number of contractions (mean (SEM)) recorded during the 24 hour test before and after healing was similar, 2055 (117) $v 2079$ (155). The percentages of

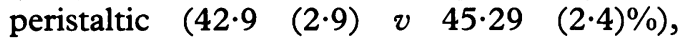
simultaneous $(10.5(1.5)$ v $10.2(1.2) \%)$, and non-transmitted contractions $(46.4(2.5) v$ $44.4(1.9) \%)$ before and after healing of oesophagitis were not different, for any of the studied time periods. Table III shows proximal and distal peristaltic contraction amplitude (Fig 1), duration and propagation velocity showed no statistically significant change after healing of oesophagitis, in any of the studied time periods, or in the low or high grade oesophagitis group.

Analysis of the two minute period after each fall in $\mathrm{pH}<4$ before and after healing of oesophagitis was technically possible in 22 patients. No statistically significant differences were found for any of the variables. In particular, the number of contractions and their 


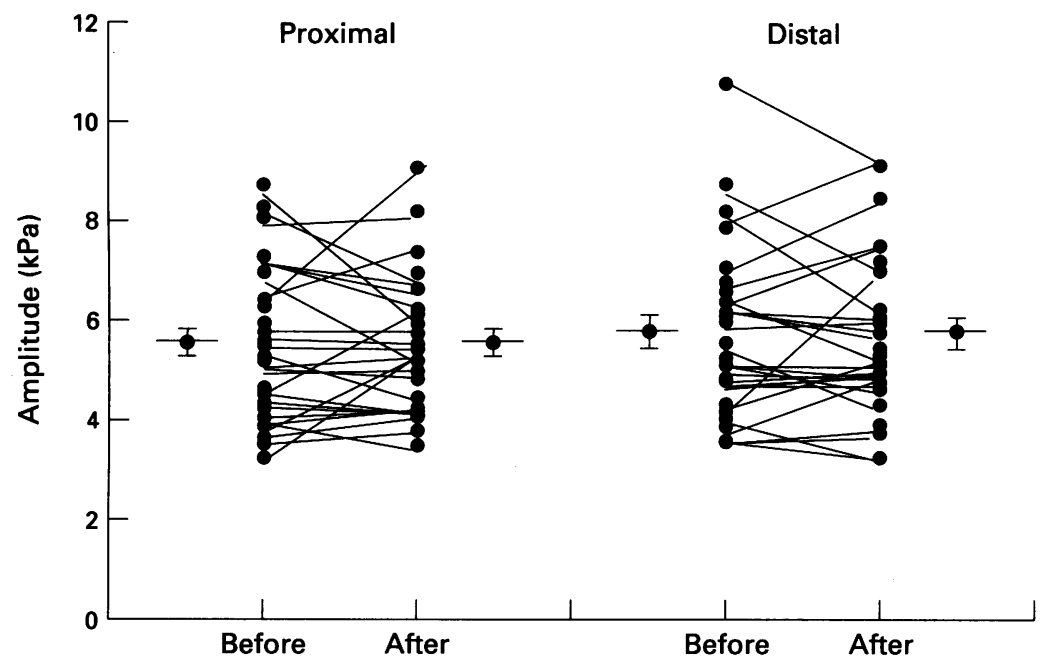

Figure 1: 24 Hour ambulatory motility data. Peristaltic amplitude in proximal $(15 \mathrm{~cm}$ above LOS) and distal ( $5 \mathrm{~cm}$ above LOS) oesophagus before and after healing of reflux oesophagitis in 27 patients. The mean (SEM) is also shown.

distribution (Fig 2) and the amplitude of the peristaltic contractions were not different before and after healing $(4.67(0.3)$ v $5 \cdot 11$ $(0.3) \mathrm{kPa}$ ), either in the total group or in the high grade oesophagitis group separately.

\section{Discussion}

Several studies have shown that oesophageal function is impaired in patients with reflux oesophagitis, especially in high grade

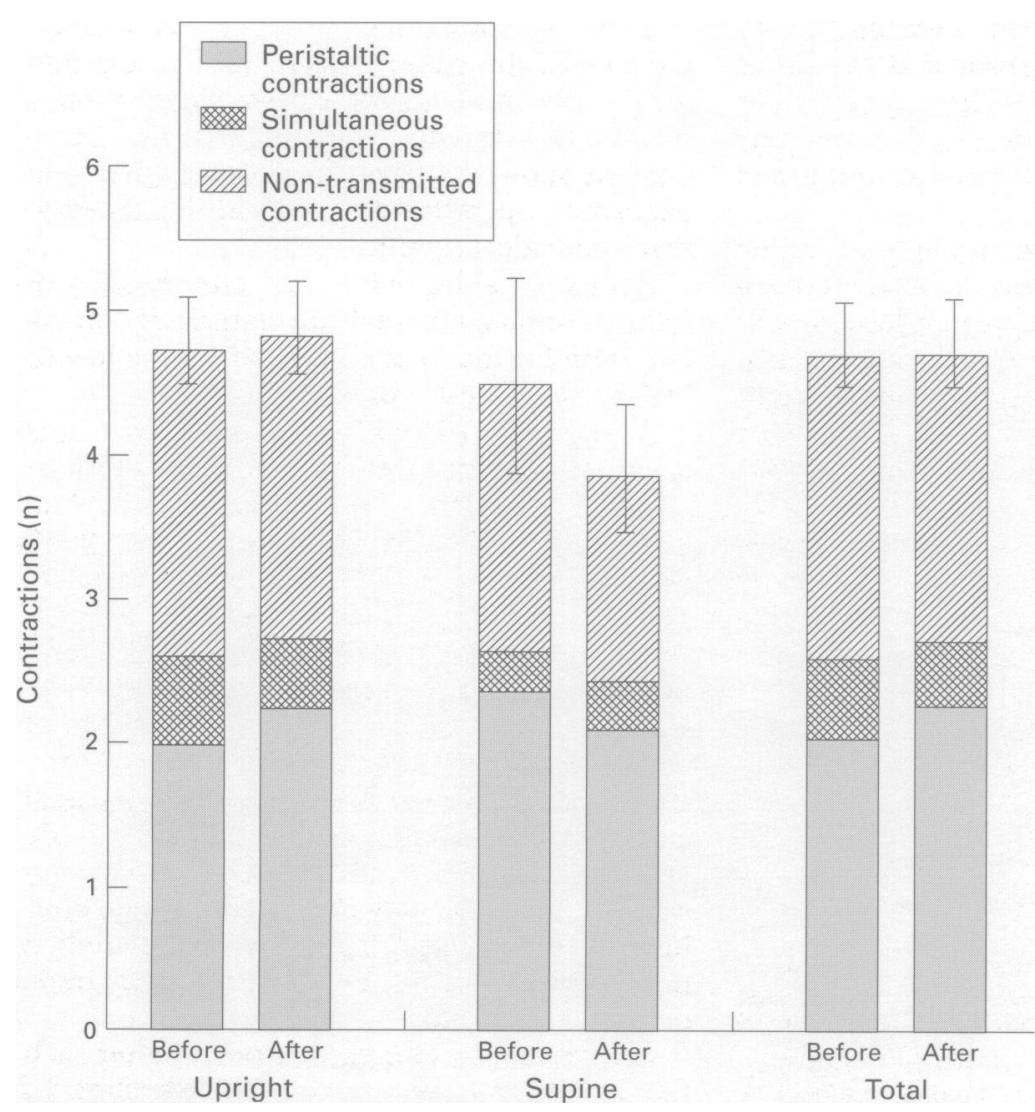

Figure 2: Number and distribution of contraction types (mean (SEM)) occurring in the two minute period after gastro-oesophageal reflux for the upright, supine, and total 24 hour period in 22 patients with reflux oesophagitis before and after healing of oesophagitis. Non-transmitted=contractions that are not propagated - that is, isolated pressure rises in the oesophagus. oesophagitis. Patients with reflux oesophagitis have reduced lower oesophageal sphincter pressures, an increased incidence of failed peristalsis, reduced distal peristaltic amplitudes, slower velocity of propagation and in some studies shorter duration of contractions. ${ }^{451011}$ Two groups have now reported that healing of oesophagitis does not improve impaired oesophageal motility. 45

We have used the new technique of 24 hour ambulatory oesophageal pressure and $\mathrm{pH}$ monitoring to assess oesophageal motility in patients with reflux oesophagitis. Twenty four hour ambulatory monitoring has the advantage of monitoring during different time periods under physiological circumstances. Recently we compared oesophageal motility in patients with low grade oesophagitis with motility data obtained in a matched normal control group. ${ }^{7}$ The propagation velocity and the duration of peristaltic contractions were found to be decreased, and the number of non-transmitted contractions to be increased in patients with grade I and II oesophagitis. Peristaltic amplitude was not shown to be impaired.

In this study we investigated oesophageal motility and $\mathrm{pH}$ profiles before and after healing of reflux oesophagitis in 27 patients with grade I-IV reflux oesophagitis. As expected, conventional manometry showed a tendency towards a decreased LOS pressure and a significantly lower amplitude and duration of distal peristaltic contractions in patients with high grade oesophagitis. During 24 hour monitoring no difference in distal peristaltic amplitude and duration was found between the low and high grade oesophagitis groups. It is considered unlikely that this is caused by the fact that in the automated analysis of the 24 hour data only pressure events exceeding two $\mathrm{kPa}$ were analysed. If this explanation were true it would be expected that there would be a decreased number of peristaltic contractions in high grade oesophagitis, which was not found in this study.

Although 24 hour ambulatory pressure monitoring is more physiological than conventional manometry, the technique was found to be less sensitive in the detection of abnormalities in peristaltic amplitude in patients with reflux oesophagitis. The usefulness of ambulatory oesophageal pressure monitoring other than in non-cardiac chest pain seems, therefore, to be limited. No significant differences were found for any of the 24 hour motility variables before and after healing of the oesophagitis.

Gastro-oesophageal reflux variables are almost identical before and after healing of oesophagitis. This is in accordance with previous studies that showed that the lower oesophageal sphincter pressure does not change after healing of oesophagitis. It also shows that oesophageal clearance is not improved by healing of oesophagitis, otherwise a shorter median duration of reflux episodes after healing of oesophagitis would be expected. This is confirmed by the results of the analysis of contractions occurring in the two periods of two minutes after each $\mathrm{pH}$ 
decrease $<4$, which also showed no effect of the healing of the oesophagitis.

In conclusion, application of the 24 hour ambulatory oesophageal pressure and $\mathrm{pH}$ monitoring technique did not show any differences in either $\mathrm{pH}$ profiles or motility variables before and after healing of reflux oesophagitis. The fact that oesophageal motility does not change after healing of oesophagitis supports the hypothesis that abnormalities in motility are pre-existent rather than the consequence of the inflammation. It could be argued, however, that the inflammation has caused irreversible changes in the oesophageal wall. A conclusive answer to the question whether reflux oesophagitis eventually leads to irreversibly impaired oesophageal motility would require a prospective study in a large cohort of reflux patients without oesophagitis, some of whom would develop oesophagitis during prolonged follow up.

1 Dodds WJ, Dent J, Hogan WJ, Helm JF, Hauser R, Patel $\mathrm{GK}$, et al. Mechanisms of gastroesophageal reflux in patients with reflux oesophagitis. $N$ Engl f Med 1982; 307: 1547-52.
2 Dent J, Holloway RH, Toouli J, Dodds WJ. Mechanisms of lower oesophageal sphincter incompetence in patients with symptomatic gastro-oesophageal reflux. Gut 1988 ; 29: $1020-8$.

3 Helm JF, Dodds WJ, Pelc LR, Palmer DW, Hogan WJ, Teeter BC. Effect of esophageal emptying and saliva on clearance of acid from the esophagus. N Engl F Med 1984; 310: $284-8$.

4 Katz PO, Knuff TE, Benjamin SB, Castell DO. Abnorma esophageal pressures in reflux esophagitis: cause or effect? Am $\mathcal{F}$ Gastroenterol 1986; 81: 744-6.

5 Singh $\mathrm{P}$, Adamopoulos A, Taylor $\mathrm{RH}$, Colin-Jones DG. Oesophageal motor function before and after healing of oesophagitis. Gut 1992; 33: 1590-6.

6 Timmer $\mathrm{R}$, Breumelhof $\mathrm{R}$, Nadorp JHSM, Smout AIPM. Oesophageal motor response to reflux is not impaired in reflux oesophagitis. Gut 1993; 34: 317-20.

7 Timmer R, Breumelhof R, Nadorp JHSM, Smout AJPM. Esophageal motility in low grade reflux esophagitis, evaluated by stationary and 24 hour ambulatory manometry. Am $\mathcal{F}$ Gastroenterol 1993; 88: 837-41.

8 Breumelhof R, Breedijk M, Akkermans LMA, Smou AJPM. An ambulatory system for 24 hour recording of esophageal motility and pH. F Ambul Monit 1988; 1: 311-20.

9 Smout AJPM, Breedijk M, van der Zouw C, et al. Physiological gastroesophageal reflux and esophageal motor activity studied with a new system for 24 hour recording and automated analysis. Dig Dis Sci 1989; 34: 372-8.

10 Kahrilas PJ, Dodds WJ, Hogan WJ, Kern M, Arndorfer RC Reece A. Esophageal peristaltic dysfunction in peptic Reece A. Esophageal peristaltic dysfunction in peptic

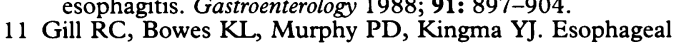
motor abnormalities in gastroesophageal reflux and the effects of fundoplication. Gastroenterology 1986; 91 364-9. 